\title{
DESENVOLVIMENTO CAPITALISTA E A PRODUÇÃO DO ESPAÇO AGRÁRIO AMAZÔNICO
}

Resumo: O desenvolvimento capitalista interfere no espaço de modo a configurar as relações sociais e de produção. Para além da dicotomia agricultura familiar e agronegócio, tem-se no espaço agrário brasileiro distintas formas de produção configuradas pelo interesse e intensidade do capital na exploração. Entre os anos 2012 e 2016, pautado na leitura do espaço geográfico, analisou-se a interferência do capital em cento e cinquenta (150) unidades de produção na Amazônia Paraense. Em resposta a lógica capitalista, foram verificados cinco (05) grupos de produtores, desde o mais integrado ao capital até a tradicional produção familiar, ratificando a hipótese do capital polimórfico ao interferir e explorar o espaço agrário.

Palavras-chave: Amazônia paraense. Capitalismo. Geografia. Produção do espaço.

\section{CAPITALIST DEVELOPMENT AND THE PRODUCTION OF AMAZONIAN AGRICULTURAL SPACE}

Abstract: Capitalist development interferes in space in order to shape social relations and production. In addition to the dichotomy of family agriculture and agribusiness, there are different forms of production in the Brazilian agrarian space, shaped by the interest and intensity of capital on the farm. Between the years 2012 and 2016, based on the reading of the geographic space, we analyzed the interference of capital in one hundred and fifty (150) production units in the Paraense Amazon. In response to capitalist logic, five (05) groups of producers were verified, from the most integrated to capital to the traditional family production, ratifying the hypothesis of polymorphic capital by interfering and exploiting the agrarian space.

Keywords: Paraense Amazon. Capitalism. Geography. Space production.

\section{DESARROLLO CAPITALISTA Y LA PRODUCCIÓN DEL ESPACIO AGRARIO AMAZÓNICO}

Resumen: El desarrollo capitalista interfiere en el espacio para configurar las relaciones sociales y de producción. Además de la dicotomía agricultura familiar y agronegocio, se tiene en el espacio agrario brasileño distintas formas de producción configuradas por el interés e intensidad del capital en la explotación. Entre los años 2012 y 2016, pautado en la lectura del espacio geográfico, se analizó la interferencia del capital en ciento cincuenta (150) unidades de producción en la Amazonia Paraense. En respuesta a la lógica capitalista, se verificaron cinco (05) grupos de productores, desde el más integrado al capital hasta la tradicional producción familiar, ratificando la hipótesis del capital polimórfico al interferir y explotar el espacio agrário.

Palabras clave: Amazonia paraense. Capitalismo. Geografía. Producción del espacio.

\footnotetext{
1 Universidade Federal do Pará, Faculdade de Geografia / Programa de Pós-Graduação em Geografia, Altamira, Brasil, herrera@ufpa.br, https://orcid.org/0000-0001-8249-5024
} 


\section{Introdução}

O pressente texto tem em seu escopo a premissa de que as mudanças ocorridas nas dinâmicas produtivas e nas relações de produção resultam da interferência do capital ao se apropriar das potencialidades, impondo-se em busca do lucro e da acumulação. Desse modo, ao analisar dinâmica do espaço agrário, sobretudo o amazônico, leva-se em consideração a interferência do capital ponderando o que Harvey (2004, p.35) definiu como "práticas imperialistas", ou seja, a exploração das condições geográficas sob as quais ocorre a acumulação do capital, aproveitando-se das assimetrias, impondo trocas não leais e desiguais entre as partes.

A centralidade deste texto está em apontar, que em geral no caso brasileiro e em especifico da Amazônia, o espaço agrário e composto por diferentes formas que vão para além da dicotomia historicamente estabelecida entre agricultura familiar e agronegócio. O fulcro na proposta está em compreender o espaço agrário a partir da sua complexidade e diversidade produtiva, principalmente, a depender da região e contexto que se desenvolve o estudo sobre o espaço agrário.

Importante destacar que neste texto assume-se uma interpretação do fenômeno que tenta buscar elementos teóricos e analíticos para interpretações geográficas acerca da realidade agrária brasileira, saindo do leque de leituras e reflexões pautadas nos paradigmas clássicos da geografia agrária. Logo, assume-se os riscos em tentar aproximar as concepções analíticas de Milton Santos para pensar a produção do espaço agrário. Noutro texto publicado, Herrera; Ramos; Silva (2014), como resultado da fase 1 do projeto, foram elucidadas as trajetórias e perspectivas dos diferentes produtores que se apresentam neste texto, a partir de uma leitura matemática e estatística, destacando a interferência da reprodução capitalista nas variáveis: rendimento agropecuário; renda extra a unidade de produção; uso da mão de obra familiar e força de trabalho contratado; relação entre a produção consumida e vendida. Mas ficou em aberto a pergunta sobre como melhor interpretar (teoricamente) a realidade nos espaços agrários e com isso foi sendo construído o caminho a partir da leitura de Santos (2007) sobre a alienação dos espaços agrícolas e o espaço entendimento como sistemas de objetos proposto por Santos (2008).

No espaço agrário amazônico, a expansão do capitalismo, historicamente, tem alterado os meios de produção e as relações de produção, de tal modo que 
substitui (aliena) os modelos tradicionais de uso dos recursos naturais por um sistema econômico integrado, globalizado, pautado na modernização e com sua forma de produção e organização do trabalho. Com isso, a exploração dos recursos naturais passa a ser feita de forma mais intensa, provocando a escassez de certos recursos, ameaçando a estabilidade ecológica e populações que não acompanham a dinâmica do capital, sendo essas exploradas ou espoliadas em detrimento da produção capitalista.

Atravessado a história de ocupação da região, que em muito foi estimulada pelo governo na década de 1970, mantiveram-se as relações arcaicas sob a dominação da minoria que concentrava recursos financeiros capazes de empreender a transformação dos recursos naturais em capital. Apesar da dominação e imposição do capital nas relações estabelecidas na Amazônia é preciso considerar a diversidade da produção, sobretudo as pautadas na lógica de reprodução familiar.

Partindo da hipótese da interferência capitalista no campo com consequência na diversidade de produção no espaço agrário amazônico, propôs em pesquisa compreender em que medida ocorre interferência do capital no espaço agrário amazônico, em especial, nas formas de produção familiar no Sudoeste Paraense.

A determinação nesta pesquisa (fase 1 - entre os anos 2008 a 2012 e fase 2 - entre os anos 2012 a 2016) para que fossem acompanhados produtores em três municípios corresponde, ao fato de existirem diferentes formas de ocupação do espaço amazônico, sendo: em Pacajá uma área de Colonização Antiga, ou seja, porções de terras destinadas às famílias no período de abertura (décadas de 1970 e 1980) da rodovia Transamazônica (BR 230); em Anapu a área acompanhada trata de dois PDS - Projeto de Desenvolvimento Sustentável, forma de ocupação que tem como objetivo o uso sustentável da floresta, sendo destinada menor porção de terra para o uso familiar com título coletivo em nome da associação responsável pela área; e em Senador José Porfírio a área é de ocupação mais recente e está organizada como um Projeto de Assentamento Convencional do INCRA - Instituto Nacional de Colonização e Reforma Agrária, com as propriedades em sua maioria no tamanho do módulo rural e em condições individuais.

Entre os produtores acompanhados nos três municípios foram mantidos ao final da pesquisa cento e cinquenta (150) produtores. A distribuição dos produtores nos três municípios foi possível devido aos projetos de pesquisas realizados pela Universidade Federal do Pará (UFPA) em parceria com outras instituições de 
pesquisa e desenvolvimento científico que contavam com maior número de produtores envolvidos. No entanto, o tratamento final indicou a necessidade de redução do número devido se prezar pela qualidade dos dados que subsidiaram as análises e interpretações que compõem este estudo.

\section{Metodologia}

Metodologicamente buscou materializar as implicações da interferência capitalista no campo. O esforço de elaboração está em verificar a realidade pesquisada, considerando a combinação de uma ordem temporal e de uma ordem espacial, adotando a leitura da realidade tendo como central "a relação geográfica mais simples, a relação homem/terra", que cada vez menos é "determinada pelas caracteristicas da área e pelo processo direto de produção, e cada vez mais um resultado do processo de organização da produção vista como um tudo" (SANTOS, 2008, p. 150).

Inicialmente o objetivo era estabelecer apenas uma tipologia com os produtores, mas a vivencia no campo e o acesso as referências geográficas possibilitaram rever os caminhos da pesquisa, sobretudo na fase 2 (entre os anos 2012 e 2016), enfatizando a necessidade de interpretar a partir dos elementos da totalidade apresentada por Santos (2005).

A delimitação analítica, seguindo a proposição de Milton Santos, possibilitou a elaboração de formulários de pesquisa e observação no campo pautados nas categorias: forma; função; estrutura, processos e totalidade, para compreender as implicações nos modos de vida e no sistema de produção adotados pelas famílias.

Durante os dois anos da fase 2, as famílias foram acompanhadas (visita as suas unidades produtivas e práticas sociais) e realizados a aplicação de formulários em dois momentos distintos do ciclo agrícola (safra e entressafra). As informações foram sistematizadas e possibilitaram a análise estatística dos dados, os quais permitiram por meio dos indicadores categorizar os produtores familiares em cinco (05) grupos: apresentado as características das unidades produtivas encontradas durante a pesquisa, dentre as cento e quinta (150) unidades produtivas acompanhadas foram identificadas: oito (08) Propriedade Patronal Latifundiária; doze (12) Empresa Patronal Capitalista; vinte e sete (27) Empresa Familiar Consolidada; cinquenta e seis (56) Produção Familiar em Transição e quarenta e sete (47) Produção Familiar Tradicional. 
Após a análise estatística os grupos estabelecidos foram verificados com as informações (entrevistas abertas e subjetivas) sobre suas trajetórias, relações sociais e cotidiano de vida, esta etapa da pesquisa validaram e ratificaram os indicadores e os grupos de produtores familiares. Partir daí seguiu buscando entender as implicações da interferência do capital nas estratégias de reprodução de cada grupo (relação homem e natureza) e os rebatimentos desses na produção do espaço agrário definido como lócus de pesquisa.

Este artigo está organizado em três seções além da introdução, metodologia e considerações finais, a saber são elas: uma possibilidade de interpretação geográfica dos espaços agrários, nesta apresenta-se o espaço geográfico e a produção do espaço como fundamentais na interpretação geográfica do campo brasileiro; a segunda seção foi definida como, a origem do capitalismo e a interferencia imposta ao espaço agrário brasileiro, mostrando como a interferencia do capital vai condicionando o espaço e redefininfo as relações no campo brasileiro; a terceira seção busca materializar o espaço agrário amazônico contemporâneo, problematizando a necessidade de se verificar o espaço agrário para além da dicotomia agricultura familiar e agronegócio para reconhecer a complexidade e as diferentes estratégias de produção, sobremaneira, determinadas pela interferência do capital.

\section{Uma possibilidade de interpretação geográfica dos espaços agrários}

A proposta no escopo deste texto passa por entender o espaço agrário de modo que o reconheça como um conjunto de fatos e fenômenos, sistema de diferentes meios e processos que se complementam e concorrem entre si como partes indissociáveis. Assim, considera-se como alternativa para se interpretar o espaço agrário a interpretação geográfica pauta na proposição feita por Santos (2008, p. 63), na qual o espaço resulta de um "sistema de objetos e um sistema de ações, um conjunto indissociável, solidário e também contraditório, não considerado isoladamente, mas integrado e que irá condicionar as ações sobre o espaço".

Para Santos (2005) o espaço é considerado como totalidade, conjunto de relações dadas por funções e formas apresentadas por processos do passado e do presente, logo, deve ser entendido como resultado e condições dos processos sociais. 
A delimitação analítica, seguindo a proposição de Milton Santos, possibilita a interpretação pautada nas categorias: forma; função; processo e estrutura.

Podemos assim ver que as noções de totalidade, escala, sistema e tempo são categorias imbricadas. Da mesma forma como a definição de cada uma dessas categorias não é possível sem a intervenção das outras, qualquer que seja a análise ou estudo que não leva em consideração todas essas categorias e todas elas ao mesmo tempo, não poderá abraçar a realidade total (SANTOS, 2005, p. 219).

A ideia de totalidade apresentada por Santos permite olhar para o espaço agrário delimitado, a realidade concreta, como "uma situação em mudança". Sendo necessário reconhecer a importância da dimensão histórica no âmbito da geografia, ou seja, não se pode ter a noção de espaço inseparável da ideia de tempo (SANTOS, 2014). Deste modo, o autor propõe o pensar a partir da lógica de períodos com formas, funções, processos e estruturas que permitem analisar um pedaço de tempo definido. De acordo o próprio autor:

Períodos são pedaços de tempo definidos por características que integram e asseguram o movimento do todo. Mas essa interação se faz segundo um controle que assegura uma reprodução ordenada das características gerais, isto é, segundo uma organização. É a falência desta última, açoitada por uma evolução mais brutal de um ou de diversos fatores, que desmantela a harmonia do conjunto, determina a ruptura e permite dizer que se entrou em um novo período (SANTOS, 2008, p.24).

Com isso, concorda-se com Lins e Rios (2010, p.63) quando apontam em seus estudos que a "delimitação temporal ou periodização regional é um procedimento que possibilita traçar uma linha evolutiva das mais diversas relações espaciais vivenciadas por determinada região" e, principalmente quando enfatizam que "na elaboração de uma periodização dos processos regionais deve-se analisar as estruturas espaciais pretéritas e desta forma definir os marcos espaciais da produção".

A exemplo desta proposição, ao estudar o espaço agrário amazônico, devese fazer transpassando os elementos quantificáveis ou materiais, buscando as simbologias que caracterizam as dinâmicas existentes. Olhando para as diferentes escalas, deve-se verificar a relação entre o homem e a natureza que contribuem na produção do espaço, ou seja, fazendo a leitura considerando a emoção, os diferentes elementos da vida social, para se chegar aos aspectos subjetivos que corroboram na produção do espaço.

Partindo da reflexão proposição, busca-se em Santos (2002) a relevância quanto a importância em ter no estudo os elementos natureza e técnica. Para o 
referido autor, a natureza é a origem e assim, tudo eram coisas no princípio e hoje tendem a serem objetos, os homens a partir de um conjunto de intenções sociais fazem das coisas objetos. Além disso, o autor deixa claro que a técnica é a relação entre o homem e a natureza, com a qual o homem realiza sua vida, produz e ao mesmo tempo cria espaços (SANTOS, 2014 p.29).

Pensar o espaço agrário, sobretudo o amazônico, parte-se da premissa, de que esse seja produto do capital, em que pese os incentivos fiscais e todos os estímulos ofertados pelos diferentes governos para concentração da propriedade dos meios de produção. Sobretudo, por se fazer confrontar o grande capital com as estruturas de produção familiar, estabelecendo, assim o estado de conflito e violências sem precedentes.

Por fim, entende-se que a produção do espaço agrário amazônico replica a imposição da lógica capitalista sobre as relações sociais e de produção. Essa problematização reforça a tese de que no Brasil em geral e em especifico na Amazônia, as condições foram sendo impostas, não respeitando os interesses locais, as necessidades vivenciadas pela população residente, mas sim os objetivos concernentes à reprodução e reconcentração do capital (SANTOS, 1989 p.34). Portanto, considera-se que o espaço socialmente construído não refletiu ou reflete os interesses e as necessidades da grande maioria dos sujeitos locais.

Para subsidiar essa reflexão acerca da produção do espaço agrário amazônico considera-se importante retomar o debate sobre as origens agrárias do capitalismo (WOOD, 2000) e a interferência da lógica de reprodução capitalista no espaço agrário brasileiro. Reflexões essas apresentadas no tópico a seguir.

\section{A origem do capitalismo e a interferência imposta ao espaço agrário brasileiro}

O fato do capital ter se desenvolvido provoca repensar a afirmação feita por Smith (1983) acerca do Capital e Agricultura. Ao ressaltar que "a natureza da agricultura não comporta tantas subdivisões do trabalho, nem a diferenciação tão grande de uma atividade para outra, quanto ocorre nas manufaturas", Smith (1983; v.1, p.42) chamava atenção para a dificuldade que o capital encontraria ao penetrar no campo, como fez noutros espaços. Tal afirmação, até caberia à época do autor, mas, atualmente, sem necessariamente depender das especificidades da divisão do trabalho o capital se apropria do espaço agrário determinando as relações sociais e de produção. 
Nesse aspecto, há concordância com a teoria apresentada por WOOD (2000) sobre "as origens agrárias do capitalismo". A autora chama atenção para a relação entre o aumento da produtividade, da lucratividade e a propriedade individual plena já existir antes mesmo da proletarização da força de trabalho na Inglaterra, inclusive sendo a responsável pelo surgimento da proletarização. O formato exclusivo e excludente de produzir expropriou os camponeses, gerando um contingente de semterra, os quais foram sujeitados aos imperativos do mercado.

Wood (2000) faz a seguinte afirmação quanto à origem do capitalismo.

[...] o capitalismo, com todo seu impulso específico de acumular e de buscar o lucro máximo, nasceu não na cidade, mas no campo, num lugar muito específico, e tardiamente na história humana. Ele requer não uma simples extensão ou expansão do escambo e da troca, mas uma transformação completa nas práticas e relações humanas mais fundamentais, uma ruptura nos antigos padrões de interação com natureza na produção das necessidades vitais básicas (WOOD, 2000, p.13).

Para a referida autora, a origem do capital está no momento em que as relações comerciais realizadas passam a ser determinadas e reguladas pelo mercado. Camponeses-proprietários, senhores de terra e funcionários se apropriavam da produção dos outros sem depender diretamente do mercado. Quando isso acontece, o mercado começa a mediar a relação entre os sujeitos e passa a existir o imperativo do capital.

Os proprietários e arrendatários ao se preocuparem com o chamado melhoramento, ou seja, com o aumento da produtividade da terra com a meta de obter lucro adotaram novas formas de concepção de propriedade, a qual previa concentração da terra, buscando eliminar as práticas tradicionais que inviabilizavam a ampliação da produção nas mesmas.

Retoma-se a história e a teoria da origem agrária do capitalismo para afirmar que o desenvolvimento capitalista e a interferência que impõe no espaço agrário não constituem uma relação da contemporaneidade ou ainda como resultado da modernização.

Carvalho (1984, p.44) afirma, ao analisar o caso brasileiro, que "a relação de subordinação ao capital das relações sociais de produção no campo, não tem seu começo no período recente quando se assiste ao processo de modernização da agricultura". Para o autor a subordinação se dá através da própria dinâmica do capital, quando constituído como relação social dominante, estabelecem sua dominação concreta às demais relações de produção pré-existentes. 
No caso brasileiro, o capitalismo na sua expansão histórica não só vem redefinindo antigas relações de produção subordinando-as ao processo global de reprodução do capital, como também, às vezes, tem engendrado relações de produção não tipicamente capitalistas, contraditórias, mas necessárias à acumulação ampliada do capital (CARVALHO, 1984 p.88).

O desenvolvimento capitalista não elimina imediatamente as formas não capitalistas. Em determinados circunstancias são mantidas as relações e as adaptam a seus interesses para garantir a apropriação do excedente gerado, subordinando direta e indiretamente o processo de produção. No Brasil, grupos econômicos apoiados em políticas governamentais operacionalizaram a investida do capital no campo com o objetivo de dinamizar as relações internacionais via mercado, fazendo uso da modernização e expandido o agronegócio pautado na exportação de monoculturas.

À medida que a penetração do capital avança no espaço agrário, por meio da modernização, são determinadas transformações nas estruturas socioeconômicas, sobremaneira nas conexões com o setor urbano-industrial. São desencadeados processos que culminam na modernização de determinados ramos da agropecuária e até mesmo na reorganização socioeconômica de unidades produtivas, como destacou Lacerda (1985).

Ocorre na agricultura uma ampla e complexa modernização de suas técnicas de produção e de distribuição. Em consequência, efetua-se uma espécie de aproximação (ou, o mais correto, uma reunificação) desse setor em relação ao restante dos mercados de insumos e de produtos, como também através de trabalho, de terra e financeiro. Ao mesmo tempo, que diz respeito à própria organização socioeconômica interna das unidades produtivas, verificam-se complexas alterações nas relações de trabalho e de propriedade vigentes no campo (LACERDA, 1985, p.19).

Ao mesmo tempo em que o espaço agrário é modernizado, com técnicas de produção e de distribuição, proporciona formas irregulares e discriminatórias. Nas palavras de Silva $(1989$, p.324) "o desenvolvimento capitalista é por si mesmo contraditório: cria e destrói; gera riqueza de um lado e miséria de outro". Consequentemente, as interferências e respostas são diferenciadas gerando em determinados casos a real integração da agropecuária à indústria, no entanto, em outros se perpetua a simbiose que ocorria entre as demais atividades econômicas e a agropecuária.

O espaço agrário brasileiro, portanto, sofre transformações significativas nos modos e na dinâmica da produção agropecuária em função da modernização. No entanto, não significam mudanças nas condições históricas das relações entre 
trabalhadores e patrões. Em verdade, ocorre a preservação das perversas características de relações arcaicas de trabalho e práticas convencionais no trato das lavouras e criações, demudando e complexificando as relações no espaço agrário brasileiro.

A difusão do progresso técnico atinge fundamentalmente o espaço agrário do Centro-Sul brasileiro, acentuando as desigualdades estruturais inter-regionais ao proporcionar alterações no perfil produtivo das unidades regionais atingidas pela modernização e mantendo o arcaísmo da produção noutras áreas do país.

Para Delgado (1985), o processo de modernização se faz perante a diferenciação e com exclusão de grupos sociais e regiões, não se tornando um processo homogeneizador do espectro social e tecnológico da agricultura brasileira. Ao fazer esta afirmação, o autor menciona que deve ser ressaltado que o projeto modernizante abrange basicamente os Estados do Centro-Sul e que as demais regiões do país não são incorporadas no processo de modernização, passando, então, a cumprir papéis periféricos na agricultura brasileira.

$\mathrm{Na}$ verdade, o que se constrói é uma trajetória no espaço agrário do país permeada pelas diferentes formas de produção agropecuária, bem como enfatizou Szmrecsányi (1991, p.83) ao referir-se à produção brasileira como altamente diferenciada, principalmente em termos regionais, técnicos e sociais.

As diferentes formas de produção constituídas no espaço agrário brasileiro engendram contradições, por umas terem sofrido o processo de modernização; outras estimuladas ou condicionadas a se industrializar; por muitas terem mantido a tradição na forma de produzir; e além daquelas que transpuseram as especificidades da agropecuária e se consolidaram como complexos agroindustriais, o agronegócio de ponta atrelado ao mercado internacional e dependente do capital externo.

Souza (1982, p.3) destaca que a condição histórica do desenvolvimento capitalista em geral se caracteriza pela reprodução de contradições no interior do próprio processo de acumulação. As formas de produção no Brasil não são eliminadas ao longo da história, mas sim condicionadas pelo time e interesse do capital que seguindo suas próprias necessidades repulsa e/ou estabelece novas relações no espaço agrário. A heterogeneidade é condição prévia para a reprodução do capital no espaço agrário brasileiro, interferindo com condições e intensidades distintas nas diferentes formas produtivas.

Desse modo, considera que não se pode interpretar o espaço agrário brasileiro como único e homogêneo. A ação do capital ocorre devido às 
especificidades que se faz de modo desigual e combinado, gerando movimentos diversos, propagando uma vasta desigualdade social e produtiva pelo país. Como bem chamou atenção Brandão (2010, p.43), "o sistema capitalista é por natureza polimórfico".

A adoção de novas práticas e técnicas na produção, buscando melhores resultados e maior participação dos produtos na exportação, faz constituir no país expressivos arranjos com o setor industrial. Isto não significa que a mudança tenha se expressado a ponto de subordinar todo o sistema a um modelo único de produção. Pelo contrário, estabeleceu no país, um espaço agrário detentor de vasta "heterogeneidade estrutural e social de produção, impregnada por tipos de organização diferenciados e com especificidades próprias nas distintas regiões" (LACERDA, 1985 p.21).

As políticas, para estimular a modernização, atreladas ao fato de que as diferenças materiais e as relações sociais estabelecidas no interior do agropecuário que, naturalmente, geram condições e objetivos de produções desiguais proporcionaram no país o aprofundamento das diferenças socioeconômicas e produtivas.

No caso brasileiro [...], as políticas de estímulo à modernização não atingiram as pequenas unidades agrícolas, especialmente as que se dedicam à produção de gêneros alimentícios de primeira necessidade (SILVA, 1982 p.30).

$\mathrm{Na}$ mesma perspectiva, Sorj \& Wilkinson (1983) afirmam que o desenvolvimento da agropecuária brasileira se fez depurando as relações capitalistas nas grandes empresas agrícolas, fortalecendo os produtores familiares capitalizados, gerando uma massa de pequenos produtores familiares pauperizados marginalizados pela baixa produtividade.

Neste sentido, o processo de valorização do capital exerce um primado sobre o processo de trabalho, isto é, a lógica da busca do maior lucro determina não somente o timing de introdução das técnicas (podendo, por exemplo, retardar a introdução de uma técnica que seria socialmente útil, mas ainda não suficientemente rentável), como também as próprias características físicas destas como os valores de uso (ROMEIRO, 1998 p.158).

A reflexão feita acerca da evolução do capital no espaço agrário corrobora a assertiva de que ao mesmo tempo em que formas de produção evoluem, na perspectiva do capital, para maior integração à indústria, fortalecendo o agronegócio exportador, outras formas são mantidas nas condições em que se encontram para servirem a manutenção e à reprodução do próprio capital. 
A diversidade no espaço agrário brasileiro se fez com imposição e favorecimento de minorias, uma vez que foi estimulada à modificação do perfil técnico e econômico das atividades agropecuárias. Nesse contexto, as pequenas propriedades, os agricultores familiares, os camponeses e dentre outras formas de produção existentes no país ficaram à margem do processo que aumentou a concentração da renda e da terra, além de reduzir o emprego e a renda dos menos favorecidos no agrário brasileiro.

O desenvolvimento das forças capitalistas tem integrado o capital financeiro e os grandes latifúndios, distanciando ainda mais os pequenos agricultores do foco das políticas públicas. A estrutura montada para servir o agronegócio é incompatível com o desenvolvimento das pequenas propriedades, que acabam tendo que se submeter à dinâmica do agronegócio ou sucumbindo em meio aos grandes latifúndios.

As transformações ocorridas no espaço agrário brasileiro fatalmente geram desigualdades estruturais e desníveis de acessos às oportunidades para diferentes formas de produção, consequentemente, condições sociais e econômicas diversas, não excluindo participação das formas familiares de produção. Esta situação se agrava nos territórios onde coexistem formas de produção tradicional e as produções de grande empreendimento em que o Estado não assiste famílias residentes do campo e/ou estimula a expansão do capital nas relações de produção.

Para Wanderley (1996, p.7), a agricultura assume atualmente uma racionalidade moderna, os produtores familiares vão se profissionalizando, de maneira que paulatinamente são retirados seus contornos de parcialidade à medida que impositariamente ou por vontade do homos economics se integram, transitoriamente e aposteriori plenamente à economia nacional.

A autora, enfatiza, nesse processo, que os "novos personagens, ou pelo menos uma parte significativa, quando comparados aos camponeses, são também, ao mesmo tempo, o resultado de uma continuidade" (WANDERLEY, 1996 p.8). Ratificando o processo no qual se considera que o capital não tem o objetivo de elimiar a produção familiar, mas sim, por meio das suas diferentes expressões, apropria-se de seus resultados sem necessariamente transfigurar suas relações.

O capital faz a apropriação garantindo mínimas condições para as famílias integrarem as dinâmicas de mercado, não necessariamente expropriando-os da terra ou rompendo por completo a racionalidade econômica das mesmas, situação que pode ser entendida como se não tivesse vontade de alterar sua realidade. Logo, 
não há explicitamente uma drástica mudança na racionalidade dos produtores familiares em função do capital, mas sim, há a interferência com a diminuição da autonomia dos desses sem que haja o comprometimento da gestão familiar nos estabelecimentos.

Tem-se no Brasil, como consta a história, o desenvolvimento capitalista adotando diferentes formas de se apropriar e determinar as relações sociais e produtivas no espaço agrário condicionando inúmeras formas de produzir ao passo em que tenta homogeneizar a diversidade sobe a égide do capital. Essa situação é ainda mais complexa quando se interpreta regiões que padecem de problemas estruturais e do anacronismo, fato, historicamente, percebido com a interferência na formação espacial da Amazônia.

\section{O espaço agrário amazônico contemporâneo}

A história da Amazônia não foi consolidada por um ou alguns fenômenos amazônicos. De acordo Costa (2000, p.49), a Amazônia "se consagra na literatura sociológica e econômica como componente do desenvolvimento agrário brasileiro a garantir, pela ampliação da chamada margem extensiva desse desenvolvimento, o atendimento dos mercados urbanos em expansão".

Outrora a Amazônia se fazia por estruturas socioeconômicas que convergiam para uma dinâmica produtiva menos agressiva, não sendo tão determinista como hoje. No entanto, o fato da Amazônia não ter sido povoada por gente e sim por interesses (OLIVEIRA, 2009 p.86) fez sucumbir às dinâmicas autóctones e substituir o regime de escambo pela estrutura de mercado. Desse momento em diante para Santos (1989 p.28) "o instituto da propriedade se torna mais rígido" e as relações de trabalho são alteradas pelas determinações do capital.

Com esse contexto, Pinto (2009, p.11) considera que "a grande característica dessa fase, vamos dizer contemporânea, da Amazônia, é que ela deixou definitivamente de ser uma área de reserva, deixou de ser um elemento de utopias e passou a ser um elemento de negócios, um elemento dos processos produtivos".

Tal circunstância, privilegiada pelo Estado, favoreceu ao processo de expansão destrutiva, que se fez fortalecendo alguns setores e, consequentemente, reestruturando a apropriação tanto do uso dos recursos naturais como da própria renda interna. Apropriação essa que em muito se caracteriza livre "cujos limites parecem ser a natureza e seu ocupante eventual” (OLIVEIRA, 2009 p.91), mas que na verdade é realizada pelo signo da mercadoria. 
Santos (1989 p.26) aponta três características que facilitaram as transformações na Amazônia: a tradição passiva e colonialista da Amazônia; a desigualdade da importância relativa dos elementos estruturantes do capitalismo; e a concentração de propriedade que se realiza às expensas de singular exclusão social dos grupos de menor renda.

Os processos de acumulação, mercantilização e de imposição do capital ocorridos sobre as dinâmicas pré-existentes, transformam o espaço agrário amazônico. O caboclo, o extrativo, o posseiro e os novos migrantes desfavorecidos são conduzidas à prática degradante de suas histórias e formações socioculturais, deixando aos poucos ou drasticamente seus meios de vida para viver o do outro. Para Santos (1989, p.28) tal fato acarreta o crescimento do regime de emprego assalariado, pequenos produtores deixam de possuir seus próprios meios de produção e se tornam, eles ou seus descendentes, assalariados na cidade ou, menos frequentemente, no campo.

A formação socioespacial da Amazônia como conjunto de sujeitos de características sociológicas distintas e diferentes racionalidades e a realidade em que se pesquisou, provocam discordar de autores que tentam estabelecer algumas estruturas sociais genéricas representativas da diversidade amazônica como é o caso de Costa (2000, p.37) que assume apenas três estruturas básicas no agrário paraense: a unidade de produção camponesa, a fazenda e a grande empresa latifundiária.

A principal discordância está no fato de agrupar as diferentes formas de produção familiar num conceito único, "unidade de produção camponesa". Entendendo e respeitando o valor histórico e o papel do campesinato na consolidação dos diferentes sistemas econômicos não dá para considerar que esse se faz com sua forma histórica presente na Amazônia, como insígnia de uma formação social tão heterogênea como a produção agropecuária familiar.

A discordância no uso da expressão unidade de produção camponesa se dá pelo fato de remeter às reflexões a um sujeito da história do pensamento econômico que no máximo, esteve presente na figura do posseiro ${ }^{2}$ num momento específico da formação socioespacial da Amazônia, no qual as relações de confronto e disputas estavam declaradas entre os sujeitos de racionalidades econômicas distintamente definidas.

\footnotetext{
2 Para o entendimento do Sujeito Posseiro na Amazônia sugere-se conferir a obra O Posseiro da Fronteira: campesinato e sindicalismo no Sudeste Paraense (GUERRA, 2001).
} 
$\mathrm{Na}$ verdade, tem-se a assertiva de que o espaço agrário amazônico possui vasta diversidade de produção e de relações sociais, que dificilmente terá sua representação de maneira correta e adequada em uma única expressão ou definição. Nesse sentido, o espaço agrário é entendido como espaço social, definido por Lefebvre (1991, p.26) "espaço (social) é um produto (social)" que tem a natureza como sua base, transformada pelo homem com seu trabalho. Segundo o referido autor, existem algumas proposições consideradas essenciais para a interpretação do espaço: as relações sociais são constituintes do espaço e é a partir delas que o homem altera a natureza; as relações sociais de produção, consumo e reprodução (social) são determinantes na produção do espaço; o espaço deve ser estudado a partir das formas, funções e estruturas; e novas relações podem dar funções diferentes para formas pré-existentes, afinal o espaço possui elementos de diferentes tempos.

Vários estudos e diagnósticos já foram realizados na tentativa de compreender as diferentes categorias ou formas de produção no Brasil e na Amazônia. No entanto, não se consegue elencar um dentre os muitos trabalhos já realizados que explicite toda diversidade da produção que compõe o agrário amazônico, não por falta de méritos, mas sim porque a ampla realidade não se faz perceptível por completo em um estudo.

É na realidade concreta que se apreendem as diferenças que dão forma e dinamização do espaço agrário, principalmente ao se tratar da Amazônia, território de conflitos e de sujeitos com distintas racionalidades que com o tempo são submetidos à tentativa de homogeneização das relações sociais e de produção por parte do capital. Portanto, representar a diversidade do espaço agrário, assumindo algumas formas de produção para exemplificar heterogeneidade estará sempre susceptível a erros.

A interpretação do espaço agrário, com melhor aproximação da realidade, deve-se ter como procedimento metodológico o diagnóstico que pondere principalmente: a) as situações ecológicas e socioeconômicas dos produtores; b) os principais sistemas de produção (práticas e técnicas); c) os principais problemas e potencialidades; e d) o engajamento dos produtores com outros agentes (comércio, bancos, agroindústrias, poder público, etc.) (FAO/INCRA, 1995 p.7).

A maioria dos estudos sobre o agrário no Brasil tem apresentado a análise a partir da dicotomia Agronegócio e Agricultura Familiar. O processo dicotômico de análise deixa a desejar ao desconsiderar os elementos da totalidade e da 
diversidade devido aos parâmetros adotados nos estudos. Bem verdade, deve-se ter o estudo da realidade concreta para precisar as formas e relações de produção, e a posteriori aproximar-se dos fenômenos inerentes a cada forma de produção para compreendê-las em suas especificidades.

No caso dos estudos a partir da dicotomia, muito já se fez para entender as repulsões e relações estabelecidas entre as duas formas de produção, no entanto os exercícios são constituídos, normalmente, como um quadro comparativo que sobremaneira omite realidades complexas existentes nos dois "mundos", principalmente quando comparadas apenas as vantagens e desvantagens de uma forma de produzir em relação à outra.

Apesar de não esboçarem as características específicas que compõem as diferentes realidades produtivas, não há demérito nos estudos realizados, já que a maioria deles subsidia a política de defesa de uma ou outra forma de produção, servindo muito mais para dar visibilidade e respaldar a necessidade de atendimento por parte dos governos do que a compreensão detalhada do espaço agrário brasileiro.

Na perspectiva de compreender a diversidade produtiva na Amazônia, entre os anos 2012 e 2016, foram feitos os esforços de pesquisa com o objetivo de verificar as distintas formas de produção presentes no interior do espaço agrário da mesorregião do Sudoeste do Pará, nos municípios de Pacajá, Anapu e Senador José Porfírio. No mapa a seguir (mapa 01) estão dispostos os pontos referentes as unidades de produção que tiveram as produtivas acompanhadas e realizadas entrevistas. 
Figura 01-Mapa de localização das unidades de produção.

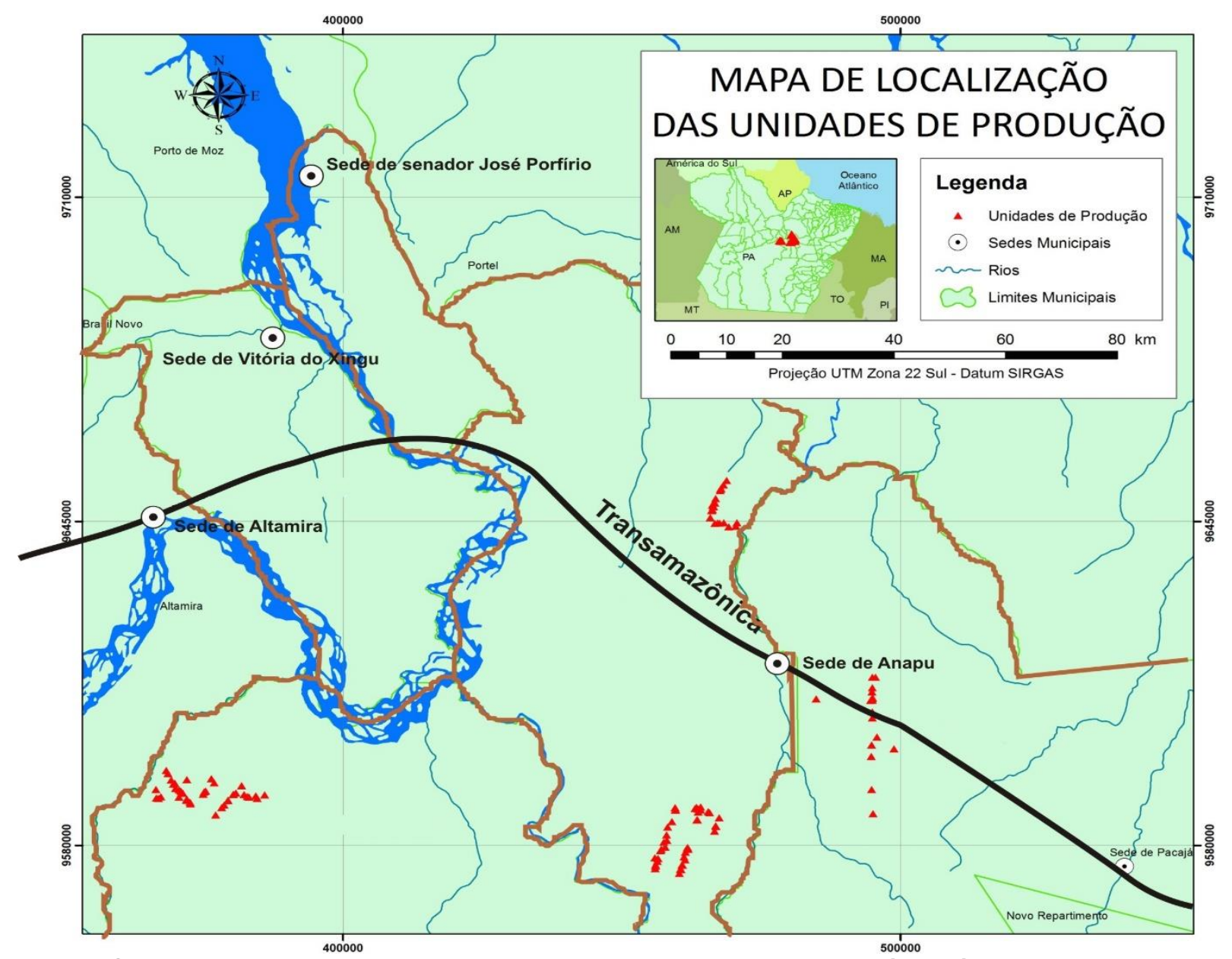

Fonte: Organização do autor partir dos dados de campo. Responsável técnico: Eder Mileno de Paula

A intenção, inicialmente, era verificar como a diversidade da produção familiar usava os recursos naturais disponíveis na Amazônia. Para isso, a Região da Transamazônica-Xingu foi delimitada locus de confrontação entre a teoria e a realidade vivenciada pelos produtores. $O$ esforço interpretativo voltava-se diretamente para os fatores que fazem da produção familiar uma categoria heterogênea, com dinâmicas específicas e dependentes das condições sociais e econômicas próprias e dos locais em que desempenham suas atividades.

No entanto, com a pesquisa e reflexões, tornou-se perceptível que a transformação das dinâmicas locais ocorria em consequência da inserção da Amazônia à economia nacional e internacional. Não sendo exagero afirmar que a concepção do modelo de ocupação da Amazônia foi de "entregação" e não de integração, conforme propaganda governamental da época. Por meio dessa "entregação" se instituiu a expansão capitalista na região e, ao mesmo tempo, as desigualdades sociais, aumentando os problemas estruturais e a interferência do 
capital sobre as diferentes formas de produção no espaço agrário amazônico contemporâneo.

A reflexão suscitou a necessidade de compreender as diferentes formas de produção, não mais, a partir apenas das práticas e condutas inerentes à família e suas condicionantes naturais, mas sim, mediante a interpretação contextualizada da integração dos produtores à economia que se constituiu na Amazônia. Sendo possível constatar que os produtores se fazem sujeitos de suas histórias, mas que essas refletem a interferência, em maior ou menor grau, do capital, não entendidas como fizeram os estudiosos pautados na economia camponesa, condicionadas meramente pelos elementos internos da dinâmica produtiva, tendo, portanto que considerar as trajetórias e relações sociais estabelecidas pelas famílias em suas localidades.

O fulcro está na compreensão de que a configuração do capital pode ser alterada para acessar as diferentes formas de produção. Tem-se, então, que a interferência nas formas de produção integradas ao conhecido agronegócio se faz com o capital que solda os diferentes capitais (industrial, financeiro, etc.), por outro lado, a interferência do capital adota o formato mercantil e suas variações para acessar e interferir noutras formas. A bem da verdade, entende-se que as relações de produção no espaço agrário amazônico, dependentes da interferência do capital, transcendem os limites da interpretação agronegócio e agricultura familiar, ou seja, a leitura dos dois polos, como normalmente são realizados nos estudos do espaço agrário. De forma que se assume, a máxima de que os interesses e condições do capital podem estabelecer sempre uma nova forma de relação social e produtiva mantendo as formas anacrônicas na perspectiva de se expandir concentrando.

Os resultados de pesquisa corroboraram para a afirmação quanto a interferência do capital no espaço agrário amazônico, sendo possível perceber a diversidade nas unidades produtivas pesquisadas a partir de variáveis que condicionam as lógicas de reprodução no campo a depender de maior ou menor interferência da lógica capitalista de produção (HERRERA; RAMOS; SILVA, 2014). A seguir é apresentado as características das unidades produtivas encontradas durante a pesquisa, dentre as cento e quinta (150) unidades produtivas acompanhadas foram identificadas: oito (08) Propriedade Patronal Latifundiária; doze (12) Empresa Patronal Capitalista; vinte e sete (27) Empresa Familiar Consolidada; cinquenta e seis (56) Produção Familiar em Transição e quarenta e sete (47) Produção Familiar Tradicional. 
a) Propriedade Patronal Latifundiária - o proprietário não mora na área, caracterizada por um conjunto de terra de grande extensão, podendo ser improdutiva ou explorada por frações de capital com técnicas predatórias, baixa ou nenhuma tecnologia adotada. Normalmente, o proprietário não depende do retorno financeiro desse sistema produtivo, assim, a força de trabalho é mínima e em condição contratual (profissionalizante).

b) Empresa Patronal Capitalista - são unidades de produção que possuem mais do que 200 há de terra, contam com alta tecnologia (mecanização total da produção e utilização racional de insumos modernos). Têm a produção especializada e em grande escala por meio da contratação de força de trabalho qualificada, voltada para o mercado, com gerenciamento capacitado para recorrer ao sistema creditício quando necessário, a grande parte apresenta dependência de capital externo à produção.

c) Empresa Familiar consolidada - unidades de produção que possuem normalmente porção de terra inferior a quatro módulos rurais com capital de exploração disponível. Além de recorrerem ao sistema bancário quando necessita de capital detêm implementos tecnológicos em parte dos sistemas de produção, adotam insumos modernos nas práticas e manejos das atividades agropecuárias. Estas semi-intensificadas com o objetivo da produção voltado para o mercado. A família mora e gerencia a unidade de produção como também executa as atividades contratando força de trabalho durante todo o ciclo agropecuário para realizar a produção.

d) Produção Familiar em Transição - é unidade de produção que possui no máximo quatro módulos rurais, dependente de baixo capital exploratório. Busca a diversificação na produção de maneira que a família ainda se consolida como mão de obra essencial. Contrata força de trabalho em períodos esporádicos e sempre em menor quantidade que o total da mão de obra familiar destinada às atividades. Tem um sistema de comercialização fragilizado, devido à escala de produção não ser tão elevada. Quando acessa o crédito bancário é sempre em proporções pequenas em relação às demais unidades de produção do setor, sendo atendida por linhas especiais de financiamento. $O$ fato de ser considerada em transição não significa que há um único sentido, muitas famílias na Amazônia retomaram ao longo do tempo suas formas tradicionais, seja por opção (ao se distanciar das relações de mercado) ou por imposição do contexto não tendendo à forma consolidada. 
e) Produção Familiar Tradicional - são unidades caracterizadas pelo uso de áreas no máximo iguais ao módulo rural, produzem de maneira diversificada e em pequena escala, comercializando, na maioria das vezes, o excedente de produção economia do excedente. A família reside na área e compõe a mão de obra para as práticas e manejos das atividades agropecuárias, mas não deixando de contar com a força de trabalho externa. A relação de pagamento em sua maioria se dá com trocas de serviços ou bens e em número menor do que a força destinada pela família ao longo da produção. Não são dependentes de maquinários ou insumos modernos para produzir e adotam práticas tradicionais na exploração dos meios de produção. O sustento da família tem sua origem basicamente no próprio sistema de produção, sem capital e de maneira muito incipiente depende do crédito bancário, quando usado é único e exclusivamente por intermédio de instituições jurídicas legais como sindicatos e associações.

Durante a pesquisa, fez a ressalva, de que essas formas de produção não estão estáticas e nem tão pouco isoladas no tempo e no espaço. Compõem um conjunto dinâmico que no seu interior estabelecem relações e repulsões, podendo desse modo, encontrar com estudos da realidade uma produção. Portanto, entendese o espaço agrário como setor aberto e dinâmico, segundo Szmrecsányi (1991, p.26), como qualquer outro sistema socioeconômico, passivo de transformações nas funções de produção. Desse modo, compreende-se o espaço agrário amazônico como complexo e dependente de interações internas e externas às relações de produção.

Destaca-se, que durante a pesquisa, ficou evidenciado a importância do fluxo de informação, o qual assume papel de relevância devido as conexões emaranhadas que certamente não deixam de enviar informações a nenhuma das formas de produção existentes, o que não significa que as informações estejam disponibilizadas de maneiras semelhantes para todos, essas são transmitidas em tempos e intensidades diferentes, afinal, é um arranjo pautado em concorrências imperfeitas e relações desiguais, características do capital atual.

Ao analisar a realidade, verifica-se que as diferentes formas de produção sofrem interferência do capital. A produção tradicional, por exemplo, devido a sua economia de excedente transfere aos intermediários seus produtos, ocorrendo apropriação de bens pelo capital normalmente com menor custo do que no interior de uma cadeia formalmente estabelecida. Não se pode afirmar que o capital queira a exclusão ou a transformação da forma de produção tradicional na Amazônia, 
cabendo à explicação quanto ao capital que toma diferentes formas para valorizar em si mesmo, apropriando-se das relações de produção possíveis no território. Dessa maneira, tem-se o entendimento que no interior do espaço agrário materializam os problemas estruturais, bem como a heterogeneidade necessária para reprodução das relações de um capital subdesenvolvido fazendo-se perverso com sua prática desigual e combinada.

É possível usar a afirmação de Oliveira (1993, p.29) quanto as relações de produção como as percebidas no agrário amazônico guardam estreita aderência com as formas de reprodução do capital. O autor enfatiza, na verdade, que é "precisamente no descompasso entre nível das forças produtivas ou formas de reprodução do capital e relações de produção que reside uma das contradições básicas do sistema capitalista de produção, o que condiciona concretizar a combinação desigual".

Há compreensão de que as relações culminam na combinação desigual do capital tendendo sempre à participação nos mercados, sejam regional, nacional ou internacional, implicando diretamente na reprodução social e produtiva das unidades inseridas no capital. O mercado nunca deixou de ser o grande regulador das relações capitalistas, mas, recentemente assume cada vez mais a capacidade de interferência direta nas lógicas de produção, sucumbindo à autonomia prévia dos produtores na determinação de suas atividades.

Tal fato se faz tanto verdadeiro quanto recorrente e para enfatizar essa condição de dependência, retoma-se a célebre obra de Santos (1989) quando explica sobre o genius da história amazônica, o mercado, e suas implicações noutros pilares institucionais da organização do sistema. $O$ autor afirma que:

Graças ao mercado mundial, os agentes de além-mar empreenderam a busca aventureira das "drogas do sertão"; por força de sua atratividade ou compulsão, deflagra-se no século XIX o surto da borracha; é também o mercado quem responde pelos planos de "valorização econômica". E certamente ele não está alheio à corrida atropelada às matérias primas da Amazônia na atualidade, às suas fontes hídricas de energia, ao regime dos "incentivos fiscais". Como tampouco o está às relações do "aviamento", bem como ao contrário, e a outras relações de produção ainda menos caracteristicamente "capitalistas", que ele recobre e inspira (SANTOS, 1989 p.39).

A citação feita na década de 1980, continua atual. Quando o autor descreve a situação acima, faz para instigar o estudo com algum detalhe como o mercado em particular e o sistema capitalista em geral engendra as relações amazônicas de 
produção, estabelecendo em todo caso, com elas, um vínculo tão tenso (SANTOS, 1989, p.39).

A reflexão feita outrora por Santos (1989) de certo modo é a que constitui o mote realizado na pesquisa, ratificando a ideia do capital interferir no espaço agrário amazônico mantendo relações anacrônicas ao mesmo tempo em que cria novas relações em detrimento à sua permanência e expansão pelo território, subsumindo os diferentes sujeitos à sua lógica de valorização em si mesmo.

A determinação por meio do mercado nas dinâmicas de produção agropecuária subsidiou Osório Silva (2000) escrever sobre a penetração imperativa do capital, assumindo que o mercado deixa de ser um mero mecanismo de intercâmbio ou distribuição e passa a ser um dos principais reguladores da reprodução social. A autora para ser mais enfática em sua reflexão, afirma:

\begin{abstract}
Esse sistema único de dependência do mercado implicou a existência de algumas "leis de movimento" muito especiais, compulsões e exigências sistêmicas específicas que nenhum outro modo de produção exigiu: os imperativos da competição, acumulação e maximização do lucro. Esses imperativos, por sua vez, significam que o capitalismo pode e deve constantemente se expandir de maneiras e em graus que outras formas sociais desconheciam - permanentemente acumulando, buscando novos mercados, impondo seus imperativos em novos territórios e em novas esferas da vida, em seres humanos e sobre o meio ambiente (OSÓRIO SILVA, 2000 p.11).
\end{abstract}

Ao trazer a reflexão de Osório Silva, para a compreensão elaborada aqui, tem-se como foco principal as "leis do movimento", as quais evidenciam a interferência do capital em todas as formas de produção, reforçando que o capital engendra as relações sociais e produtivas que convêm à sua própria reprodução, expansão e valorização. Não possibilita reduzir a existência do capital a uma única forma capitalista, bem como não se pode acreditar que há formas de produção alheias às interferências do capital no espaço agrário.

Podendo assim, afirmar que o capital condiciona formas diferenciadas de produção, dependendo da frequência e volume em que expressa seus interesses na forma de produção que interfere. Mas também, que determinadas formas de produção agropecuária, muito embora estejam inseridas ou participem dos mercados, não deixam alterar suas estratégias de produção e reprodução social. Nesses casos, o capital se apropria da forma no momento da circulação do produto e não diretamente na produção sem deixar de explorar os sujeitos.

O fato é que o estudo do espaço agrário, sobremaneira o amazônico, deve ser compreendido como sistema heterogêneo, constituído por dinâmicas e formas 
distintas de produção, as quais normalmente são determinadas pelo capital na tentativa de homogeneização das relações para se valorizar em si mesmo. Mais que isso, para que os resultados sejam satisfatórios é preciso considerar as especificidades de cada forma de produção, as relações no espaço agrário e as interações existentes entre os diferentes sujeitos que trabalham e transformam a natureza, por tanto, a dinamização e reestruturação do espaço agrário precisam ser ponderadas.

\section{Considerações Finais}

O desenvolvimento capitalista brasileiro interfere em diversos aspectos na produção do espaço agrário amazônico. Nesse sentido, concorda-se com Santos (1989 p.26) ao afirmar que "a persistência da tradição da Amazônia, tem seu crescimento orientado exogenamente, de modo como se permanecesse voltada para fora de si mesma".

A condição de voltada para fora não elimina o velho estilo de produção o que ocorre é um "realinhamento no esquema de dependência" (SANTOS, 1989 p.27). É o espírito econômico que passa a operar na Amazônia apliando a desigualdade ao alterar os valores antes adotados pela população.

O espaço agrário amazônico, portanto, é reconfigurado favorecendo os empreendimentos capitalistas, estabelecendo uma dinâmica de alteração nas formas de produção e das relações pré-existentes. O favorecimento ao avanço capitalista foi explicitado por Carvalho (1984) ao enfatizar que "a estratégia de ocupação delineada nos planos de desenvolvimento regional [...] estabeleceu uma nova política de desenvolvimento econômico, centrada no grande capital monopolista com apoio estatal", gerando um movimento complementar e contraditório.

No estudo, entre 2012 e 2016, verificou que o capital avançou sobre os espaços agrários amazônicos, impondo sua lógica por meio das diferentes formas de apropriação, espoliação e convencimento. Desencadeado pelo processo de redefinição das relações sociais, configurando um espaço agrário pautado pela coexistência e disputa de racionalidades quanto à posse da terra, ao uso dos recursos naturais e a expectativa de reprodução social.

Apesar das transformações ocorridas com a produção agropecuária de base familiar, percebe-se que a mesma não foi eliminada, pelo contrário essa ao responder aos estímulos procurou se adaptar para se fazer sujeito do território em 
construção. Verificou-se que, na verdade, a transformação mediante a interferência do capital ao aproximarem as famílias cada vez mais das relações capitalistas, moldando as diferentes racionalidades na tentativa a partir dos interesses do capital. Nesse sentido ratifica-se a hipótese de que há diferentes formas de produção e estratégias de reprodução social, criando mecanismos diversos e recorrendo as inúmeras alternativas para se viabilizarem no espaço agrário.

O estudo apontou ainda um contraponto em relação à afirmação feita por Lênin (1980 p.45) que "a tendência fundamental e principal do capitalismo consiste na eliminação da pequena produção pela grande". Para o autor, a eliminação seria um processo de ruína, não como uma expropriação imediata, com uso excessivo do trabalho, com o endividamento e sem progresso técnico, portanto traduzido na deterioração do pequeno produtor até o seu fim.

A situação descrita por Lênin ao estudar o capitalismo e agricultura nos Estados Unidos da América não se aplica, pelo menos, para a Amazônia de hoje. Os produtores agropecuários familiares não tendem a ser eliminados pelo capital, mas impõem às famílias a condição de trabalhador para o capital. Ao invés de eliminá-los do espaço agrário há o processo de valorização das desigualdades e adversidades como meios de se obter lucros facilitados e, consequentemente, a acumulação do capital.

A afirmação tem como subsidio a reflexão feita por Carvalho (1984 p.321), quem enfatizou em seu estudo sobre o capitalismo na Amazônia que o desenvolvimento capitalista na agricultura brasileira implica não só na transformação direta da produção agropecuária em bases especificamente capitalista, mas também tira proveito das condições desfavoráveis que encontra.

Por fim, assume-se que o capital, não presa pela transformação completa da base produtiva dos produtores familiares agropecuários e não tão pouco primar pela eliminação desses. Uma vez que se observou velhas condições e relações ao mesmo tempo em que são produzidas outras novas. As velhas e novas dinâmicas esboçaram a interferência do capital seja na etapa de produção seja na circulação dos produtos. A diversidade encontrada, permite afirmar que para além do debate agricultura familiar e agronegócio faz jus compreender as distintas dinâmicas de produção que compõe o espaço agrário. Entendendo que essa dicotomia impossibilita a leitura ampliada e complexa dos processos existentes nas diferentes relações de produção no espaço agrário amazônico em especifico e em geral no caso brasileiro. 


\section{REFERÊNCIAS}

BRANDÃO, C. A. Acumulação primitiva permanente e desenvolvimento capitalista no Brasil contemporanêo. In: ALMEIDA, Alfredo Wagner Berno de et al... Capitalismo globalizado e recursos territóriais: fronteiras da acumulação no Brasil contemporanêo. Lamparina. Rio de Janeiro. 2010. 349 p.

CARVALHO, David F. Formas de acumulação e dominação do capital na agricultura e campesinato na Amazônia. Dissertação. NAEA/UFPA. Belém. 1984. 239 p.

COSTA, Francisco de Assis. Formação Agropecuária da Amazônia: os desafios do desenvolvimento sustentável. UFPA. NAEA. Belém. 2000. 355p.

DELGADO, Guilherme da Costa. Capital financeiro e agricultura no Brasil. Editora da UNICAMP. Campinas - São Paulo. 1985. 240 p.

FAO/INCRA. Análise diagnóstico de sistemas agrários: guia metodológico.

FAO/INCRA. Brasília. 1995. 65 p.

GUERRA, Gutemberg Armando Diniz. O posseiro da fronteira: campesinato e sindicalismo no Sudeste Paraense. UFPA/NAEA. Belém. 2001. 170 p.

HARVEY. D. O novo Imperialismo. 2 eds. Edição Loyola, São Paulo, 2004. 201 p.

HERRERA, J. A.; RAMOS, P. SILVA, J. U. Barata da. Novas estratégias produtivas na Amazônia: estudo sobre os produtores agropecuários familiares no sudoeste paraense. Revista de Economia e Sociologia Rural/ SOBER - vol. 52. Brasilia: SOBER. 2014. P. 223-242.

LACERDA. Guilherme N. de. Capitalismo e produção familiar na agricultura brasileira. IPE / USP. São Paulo. 1985. 164 p.

LEFEBVRE, H. The Production of Space. Tradução: Donald N. Smith. Blackwell Publishing (USA), 1991. $454 \mathrm{p}$.

LINS, R. O.; RIOS, R. B.; Periodização como metodologia de análise regional: o caso da região de amargoso - Bahia. Geografia: ensino \& pesquisa. Santa Maria, v. 14, n. 2. 2010. p. $62-70$.

OLIVEIRA, Francisco de. Elegia para uma re(li)gião: Sudene, Nordeste planejamento e conflitos de classes. 6 Ed. Paz e Terra. Rio de Janeiro. 1993.

OLIVEIRA, Francisco de. A reconquista da Amazônia. In. D'INCAO, Maria A.; SILVEIRA, Isolda M. da (Orgs.). A Amazônia e a crise da modernização. ICSA/UFPA; Museu Paraense Emílio Goeldi. Coleção Eduardo Galvão. Belém. 2009. 590 p.

OSÓRIO SILVA, Lígia. Introdução ao texto de Ellen Meiksins Wood, "As origens agrária do capitalismo". In: Crítica Marxista, N. 10. Boitempo Editorial. São Paulo. 2000. 9 $-11 \mathrm{P}$.

PINTO, L. Flávio. A Amazônia entre estruturas desfavoráveis. In. D'INCAO, Maria A.; SILVEIRA, Isolda M. da (Orgs.). A Amazônia e a crise da modernização. ICSA/UFPA; Museu Paraense Emílio Goeldi. Coleção Eduardo Galvão. Belém. 2009. 590 p. 
SANTOS, Milton. Da totalidade ao lugar. EdUsp. São Paulo. 2005. 176 p.

São Paulo, 2007. 205 p.

Economia espacial: críticas e alternativas. Editora da Universidade de

A natureza do espaço: técnica e tempo razão e emoção. 4 ed. São

Paulo. Editora da Universidade de São Paulo. 2008. 384p.

2014. 120p.

Espaço e método. São Paulo. Editora da Universidade de São Paulo.

SANTOS, Roberto A. O genius de uma economia: reflexões e propostas sobre 0 desenvolvimento da Amazônia. In: ARAGON, Luis E.; IMBIRIBA, Maria de Nazaré Oliveira. Populações humanas e desenvolvimento amazônico. Série Cooperação Amazônia. UFPA. Belém. 1989. 351 p.

SILVA, J. G. da. A gestão das políticas na agricultura brasileira moderna. In. Revista de economia e sociologia. Sociedade Brasileira de Economia Rural - SOBER. Brasília. Vol. 27. N. 3, jul./ago. /set. 1989. 309-326 P.

SMITH. Adam. A riqueza das nações. Volume 1. Ed. Abril Cultural. São Paulo. 1983. 412 p.

SORJ, B.; WILKINSON, J. Processos sociais e forma de produção na agricultura brasileira. In: SORJ, B.; ALMEIDA, M.H.T. Sociedade e política no Brasil pós-64. São Paulo: Brasiliense, 1983. P.165-190.

SOUZA, José Stênio Gonzaga de. Agricultura: relações sociais de produção não capitalistas e/ou capitalistas? Dissertação de Mestrado. UFPA / NAEA. Belém. 1982. 95 p.

SZMRECSÁNYI. T. Pequena história da agricultura no Brasil. Contexto. São Paulo. 1991. $71 \mathrm{p}$.

WOOD, Ellen Meiksins. "As origens agrária do capitalismo". In: Crítica Marxista, N. 10. Boitempo Editorial. São Paulo. 2000. 11 - 29 P.

\section{NOTAS DE AUTOR}

CONTRIBUIÇÃO DE AUTORIA

José Antônio Herrera - - Concepção. Coleta de dados, Análise de dados, Elaboração do manuscrito, revisão e aprovação da versão final do trabalho

\section{FINANCIAMENTO}

A publicação resulta do apoio financeiro para pesquisa de campo do Conselho Nacional de Desenvolvimento Científico e Tecnológico (CNPq), processo: 457074/2014-0.

CONSENTIMENTO DE USO DE IMAGEM

Não se aplica.

APROVAÇÃO DE COMITÊ DE ÉTICA EM PESQUISA

Não se aplica.

CONFLITO DE INTERESSES

Não se aplica. 
LICENÇA DE USO

Este artigo está licenciado sob a Licença Creative Commons CC-BY. Com essa licença você pode compartilhar, adaptar, criar para qualquer fim, desde que atribua a autoria da obra.

\section{HISTÓRICO}

Recebido em: 01-02-2019

Aprovado em: 03-03-2019 